\title{
A Reconstrução Normativa e o Caráter Social da Liberdade em Axel Honneth
}

[Normative Reconstruction and Social Character of Freedom in Axel Honneth]

\section{Leonardo Correia Bastos»}

\begin{abstract}
Resumo: O presente objeto de pesquisa busca proceder ao estudo e identificação dos traços essenciais envolvidos na abordagem teórica das relações sociais e políticas trazidas na obra $O$ Direito da Liberdade do filósofo alemão Axel Honneth. Faz-se uma análise da influência hegeliana sobre o conceito de liberdade, assim como dos fatores relacionados com o suprimento das carências subjetivas, mediadas pelas diferentes "esferas" sociais. Honneth, assim, procura trazer à tona a compreensão de um novo modelo de liberdade advindo da Filosofia do Direito de Hegel, o qual se distingue substancialmente dos modelos tradicionais. O autor busca evidenciar a limitação das teorias da justiça de tradição liberal, invocando a necessidade de uma visão integrada das relações sociais experimentadas nas esferas referidas por Hegel, concebendo-se uma experiência concreta de liberdade social. Nesse sentido, evidencia-se o caráter interdisciplinar e emancipatório do método de reconstrução normativa como base teórica para a justificação pública nas sociedades modernas.
\end{abstract}

Palavras-chave: Relações sociais e políticas. Liberdade Social. Reconstrução normativa. Sociedades modernas.

\begin{abstract}
This research object aims to study and identify the essential traits involved in the theoretical approach of social and political relations brought in the work Freedom's Right by the german philosopher Axel Honneth. It analyses the hegelian influence on the concept of freedom, as well as the factors related to the supply of subjective needs, mediated by the different social "spheres". Honneth thus seeks to bring to light the understanding of a new model of freedom stemming from Hegel's Philosophy of Law, which differs substantially from traditional models. The author seeks to highlight the limitation of liberal theories of justice, invoking the need for an integrated view of the social relations experienced in the spheres referred to by Hegel, conceiving a concrete experience of social freedom. In this sense, the interdisciplinary and emancipatory character of the normative reconstruction method is evidenced, as a theorical basis for public justification in modern societies.
\end{abstract}

Keywords: Social and political relations. Social freedom. Normative reconstruction. Modern societies.

\footnotetext{
${ }^{*}$ Mestre em Filosofia pela Universidade de Brasília (UnB). Bacharel em Direito pela Universidade Católica de Pernambuco. E-mail: lcorreiabastos@gmail.com. ORCID: https://orcid.org/0000-0001-8260-4892.
} 
1. Os modelos de liberdade, a função das instituições sociais e o reconhecimento recíproco como herança da filosofia hegeliana

Honneth principia o primeiro capítulo da sua obra O Direito da Liberdade referindo-se às diferentes concepções de liberdade. Inicialmente, há a abordagem histórica e conceitual das acepções tradicionais da liberdade, relativas à liberdade negativa e à liberdade reflexiva, bem como de seus conteúdos essenciais de caráter individualista e contratual, e de autonomia moral, respectivamente. Já na seção dedicada à liberdade social, o autor propõe a tese de que somente por meio de interações intersubjetivas, no discurso da liberdade, é que as instituições da realidade social serão tidas como meio para o próprio exercício da liberdade, e não como elementos adicionais a sua satisfação.

Em contrapartida ao que denomina de "transcendentalismo" e "institucionalismo" da teoria do discurso em Habermas, Honneth afirma que, sem a presença de estruturas institucionais de prática da autodeterminação recíproca, fica impossibilitada a obtenção de uma "intersubjetividade da liberdade". O autor, então, salienta que Hegel elaborou uma concepção própria de liberdade, à qual se deve atribuir uma denominação "social". Hegel vai, assim, partir de uma crítica às concepções de liberdade negativa e de liberdade reflexiva. A liberdade nega- tiva fracassa por ser desprovida de conteúdo concreto, a ela se opondo uma realidade social, dada de modo alheio ao seu exercício efetivo. Já no que diz respeito à liberdade reflexiva, a crítica hegeliana passa pela ausência de uma exteriorização das determinações subjetivas baseadas na ideia de autolegislação do indivíduo relativamente a uma autonomia de conduta e de realização de seus desejos autênticos. De tal modo, aponta Honneth que o objetivo de Hegel seria a compreensão de um novo modelo de liberdade, capaz de suprir tais insuficiências e de promover um critério intersubjetivo de liberdade cuja função é a de determinar as demais formas objetivas existentes. Como consequência, "[...] não só as intenções individuais deveriam satisfazer ao padrão de ter surgido sem nenhuma influência estranha da sua parte, mas também se deve poder apresentar a realidade social externa livre de toda heteronomia e de toda coerção." (HONNETH, 2015, p. 84). Todavia, observa o autor a dificuldade inerente a essa concepção hegeliana de liberdade, tomando como parâmetro a insuficiência de critérios que possam dar correta indicação da liberdade efetiva ainda na esfera dos projetos e objetivos individuais. Nesse sentido, a carência de intuições/critérios relativos à realidade social se mostra completa.

Honneth afirma que, na nota ao $\S 7^{\circ}$ da Filosofia do Direito, Hegel procura dar indícios da experiência cotidiana 
para fazer frente à esfera social nas figuras da "amizade" e do "amor". Com respeito a isso, o autor vai assim aduzir acerca da liberdade social em Hegel:

\section{[...] a chave de sua concepção de liberdade social está contida} na formulação do "estar consigo mesmo no outro", utilizada para esse fim; ela se baseia numa ideia de instituições sociais que, assim sendo, permite aos sujeitos se relacionarem uns com os outros, já que eles poderiam compreender sua contraparte como outro de si mesmos. (2015, p. 85).

A categoria do reconhecimento recíproco, conforme Honneth, é elemento primordial e chave para a compreensão do ideal hegeliano de liberdade. Desse modo, explica-se que o desejo subjetivo de liberdade só passa a uma concretização exterior por meio do encontro intersubjetivo com o "outro" e suas respectivas aspirações. Na dimensão do reconhecimento recíproco, há, em primeiro lugar, a confirmação de si próprio refletido pelos desejos da contraparte subjetiva, representando esta "uma condição da realização dos próprios desejos e fins" (2015, p. 86). Em continuidade, Honneth aponta que, dessa complementariedade recíproca, há uma ampliação da liberdade subjetiva e sua conversão numa "liberdade intersubjetiva".
É preciso, ainda, ressaltar a necessidade de instituições e de práticas padronizadas de comportamento que possibilitem a compreensão mútua na articulação e reconhecimento dos respectivos fins e desejos, tratada na abordagem hegeliana. Conforme sintetiza Honneth, a concepção hegeliana de liberdade está fundada no reconhecimento recíproco proporcionado no âmbito de instituições sociais, expressando-se por meio do entrelaçamento de práticas de comportamento compartilhadas intersubjetivamente, em direção à satisfação dos desejos de cada agente (2015, p. 86). Ainda segundo o autor, a noção de liberdade intersubjetiva, em Hegel, eleva-se a um conceito "social" de liberdade. Nesse sentido, a liberdade do sujeito depende de um ambiente social/institucional no qual ele possa vivenciar uma conexão de relações de reconhecimento recíproco. Explica que as instituições sociais representariam a forma de manifestação do "ser em si mesmo no outro" pensado por Hegel, "[...] uma vez que somente práticas harmonizadas e consolidadas fazem que os sujeitos compartilhados possam se reconhecer reciprocamente como outros de si mesmos." (2015, p.87).

Já com a concepção do amor, Hegel faz referência a uma relação pensada institucionalmente e socialmente condicionada para que se possibilite uma relação de reconhecimento. Também a esfera própria do mercado exerce a mediação de ações cuja possibilidade de 
explicação não seria possível sem a presença de um potencial próprio de liberdade. Assim, pode-se afirmar que, para Hegel, a relação de reconhecimento recíproco formadora da liberdade está sempre ligada a uma instituição socialmente constituída. Nesse ponto, o mercado ocupa o papel institucional de reconhecimento na satisfação dos interesses/necessidades econômicas dos sujeitos. Oportuna a observação, nesse ponto, de que:

[...] como Hegel pode inferir, a liberdade tem a estrutura institucional de uma interação, pois só mediante o reconhecimento recíproco de um sujeito pelo outro é que os indivíduos podem chegar à satisfação de seus fins. Conceber o mercado como uma forma nova e indireta do "em-si-do-si-mesmo no outro" significa aprender a entender que essa instituição cria uma relação de reconhecimento pela qual os indivíduos podem ampliar a sua liberdade. (2015, p. 89).

Honneth assinala que a conclusão a que chegou Hegel acerca da concepção de liberdade tem raízes puramente lógicas, como efeito da superação da ausência de um conceito puramente negativo de liberdade; bem como da falta de objetividade da liberdade interna/reflexiva. No esforço de dar plau- sibilidade às suas conclusões, Hegel busca uma maior aproximação com a concretude da experiência cotidiana, objetivando, assim, a inclusão de um caráter objetivo na determinação da liberdade. Conforme pontua Honneth, "O mundo da objetividade deve ir ao encontro da aspiração à liberdade individual no sentido de que ela, em certa medida, deseja de si o que o sujeito reflexivamente pretende." (2015, pp. 91-92). Ainda para o autor, uma exigência de tal natureza apenas é viabilizada pela convivência com outros sujeitos imersos numa mesma realidade externa, na qual as condicionalidades teleológicas existentes traçam o caminho a ser percorrido pelo sujeito na busca de realização de suas vontades (2015, p. 92).

Dessa forma, temos a necessidade de uma relação de reconhecimento recíproco, cujo alcance da noção de liberdade passa, obrigatoriamente, por uma complementariedade que a condiciona. Assim, entende-se que a manifestação da liberdade individual, de forma objetivamente realizável, pressupõe uma sinergia intersubjetiva atuante no desejo individual para o alcance de fins complementares. Em consequência, passa a assumir uma função fundamental na formulação hegeliana a existência de instituições responsáveis pela condução e concretização de práticas que venham a ser alinhadas socialmente na consecução dos fins subjetivos. O autor identifica, portanto, 
na proposta hegeliana, a existência de duas tarefas distintas a serem satisfeitas pelas instituições responsáveis pelas relações duradouras de reconhecimento. Num primeiro plano, elas realizam uma mediação para que os comportamentos individuais venham a ser reciprocamente compreendidos e, desse modo, sejam projetados fins complementares a serem atendidos em participação conjunta. Por outro lado, tais instituições são responsáveis pela conscientização da liberdade intersubjetiva, em que os indivíduos compreendem a dimensão da adaptação de práticas intersubjetivas com objetivo na consecução de fins subjetivamente complementares, os quais levam a um aprendizado que assegura uma formação comunitária garantidora de liberdade entre membros autoconscientes dentro da sociedade.

Segundo Honneth, Marx não estaria numa posição muito afastada da noção hegeliana de reconhecimento, pois faz depender a liberdade de autorrealização individual da relação complementar com outros sujeitos. Por meio das relações de trabalho, as quais são caracterizadas pela sua incompletude, "todos estão ligados entre si mediante relações de reconhecimento, de modo que em seu trabalho confirmam reciprocamente a dependência um do outro" (2015, p. 97). Marx e Hegel conceberiam a liberdade individual de maneira a não compartilhar com o modelo idealista, contrariamente, ambos compre- endem que a realização de liberdade reflexiva do sujeito depende de uma correspondência na realidade externa por um outro sujeito mediante uma relação de reciprocidade. Honneth vai apontar para o papel das instituições em Hegel, as quais se efetivam na própria estrutura de intersubjetividade social, representadas pelas "práticas harmonizadas e objetivadas numa estrutura institucional" (2015, p. 102). Conforme observa Honneth, não haveria em Hegel a defesa de nenhuma instituição específica como constituinte do conceito de liberdade, "[...] na verdade, tem de se limitar a estruturas institucionais nas quais são fixadas as relações de reconhecimento, que possibilitam uma forma duradoura de realização recíproca de objetivos individuais." (2015, p. 102). Nesse aspecto, é crucial a posição exercida pelo conceito de reconhecimento, cuja atuação se dá na relação de intersubjetividade, formadora da liberdade presente nas instituições sociais. Isto se dá pela via da normatividade das ações institucionalmente reguladas e modeladas como vias de acesso à realização individual e de reconhecimento recíproco dos agentes sociais.

Honneth enuncia que Hegel e Marx se colocam frontalmente em contrariedade à posição contratualista dos teóricos liberais e ao conceito de liberdade negativa como instrumento de justiça social. Todavia, enquanto Hegel também faz críticas às teorias da justiça 
da tradição liberal, Marx não se ocupa de tal questão, por acreditar no viés legitimador da classe dominante exercido pelos princípios de justiça puramente abstratos. Para Hegel, mostrase equivocada a formulação kantiana, já que "tais teorias se enredam num círculo vicioso, pois em sua construção do ponto de vista processualista já teria de ser pressuposta toda uma cultura da liberdade, cujas situações [... ] não poderiam ser fundamentadas" (2015, p. 105). As teorias de viés formalista/procedimentalista se limitam a abordar unicamente a liberdade individual em seu aspecto subjetivo, deixando de fora a realidade social exterior, na qual o indivíduo se situa, bem como a realidade institucional da sociedade. Assim, conforme Honneth, podese aduzir que há, em Hegel, uma visão que rejeita a separação entre os fundamentos teóricos e os procedimentos de justificação aplicáveis, o que leva a concluir que, "[...] se o pressuposto conceito de liberdade já contém em si as indicações de relações institucionais, de sua exposição deve resultar, de modo quase natural, a suma essência de um ordenamento social justo." (2015, p. 106).

A crítica de Hegel ao procedimentalismo abre espaço para uma fundamentação diversa da teoria da justiça, por meio de uma absorção pela realidade institucional dos próprios fundamentos da liberdade individual. Nesse aspecto, Honneth observa que, para Hegel, apresenta-se o problema de saber previamente quais os objetivos passíveis de realização pela via da "intermediação institucional em reciprocidade livre de coerção" (2015, p. 107). Segundo o autor, diferente de Kant, Hegel não pode se ater a uma atribuição ilimitada a todos os objetivos e intenções morais subjetivas, uma vez que "para a realização da liberdade intersubjetiva, de antemão ele deve estabelecer os fins que poderiam ser alcançados pelos indivíduos em conjunto e de maneira recíproca" (2015, p. 107). Em continuidade à sua análise, o autor avalia caber a Hegel identificar, antecipadamente, os fins universalmente próprios da liberdade, dentro de uma perspectiva teórica social e filosófica. É necessária, assim, uma conceituação formal dos objetivos intrínsecos aos sujeitos racionais para um posterior alinhamento em consonância com as opções dadas empiricamente na realidade exterior.

Mesmo ciente das intenções de fundamentação metafísica da liberdade, dentro do panorama da filosofia da história de Hegel, Honneth propõe a empregabilidade do método hegeliano fora de sua metafísica do espírito. O tema central analisado por Hegel situa-se na busca de satisfação da liberdade individual pelo sujeito e de como esse fim se dá em meio a uma complexa rede institucional de reconhecimentos recíprocos na sociedade moderna. Assim, o autor aponta que 
"[a] quantidade de instituições, que Hegel diferenciou, é analisada aqui estritamente com a quantidade de objetivos que ele acredita poder susbsumir aos indivíduos como objetivos universais na modernidade" (2015, p. 109), isso tendo em vista a necessária correspondência entre a estrutura institucional e os padrões relacionais de reciprocidade, a fim de que se viabilize de modo duradouro a satisfação dos desejos pela via da intersubjetividade. Nesse âmbito, a justiça de um ordenamento social será realizada apenas quando efetivamente forem garantidos os meios institucionais de liberdade, não se podendo manifestar como mero "reflexo fiel do resultado de um contrato social fictício ou de uma construção de vontade democrática" (2015, p. 109). O alcance efetivo da liberdade pelo sujeito apenas pode ser concebido com a sua integração dentro de esferas sociais que lhe possibilitem agir de modo livre como agente social, ultrapassando a mera potencialidade garantida dentro do ordenamento de uma sociedade. Destaca Honneth que o alcance da liberdade individual está intimamente ligado à existência de instituições socialmente justas, de modo que o embasamento da teoria da justiça em Hegel "decorre de uma apresentação de relações éticas, de uma reconstrução normativa daquele ordenamento escalonado de instituições, nas quais os sujeitos podem realizar sua liberdade social experimentado o reconhecimento recíproco." (2015, p. 110).

A construção metodológica hegeliana se consuma na garantia dada aos indivíduos de avaliação constante de que as instituições de realização da liberdade social estão sendo capazes de possibilitar a efetivação das garantias concebidas pelo Estado, tomando uma posição em que possam visualizar criticamente suas próprias relações dentro dos respectivos processos institucionais. Apesar de reconhecer a importância do papel exercido pelo "direito abstrato" e pela "moralidade" para o funcionamento das liberdades individuais, tais expressões da liberdade estão, para $\mathrm{He}$ gel, subordinadas às formas institucionais de efetivação da liberdade social. Nesse sentido, Honneth irá fundamentar que os "aparatos institucionais" responsáveis pelas complexas relações de reconhecimento recíproco não estão associados, na teoria hegeliana, a procedimentos de consenso prévio da totalidade dos membros da sociedade. Isso se justifica à razão de que, "por falta de integração institucional, os sujeitos ainda não seriam suficientemente livres para efetivamente poderem ter uma opinião e uma perspectiva ponderada" (2015, p. 112). Dessa forma, Honneth explana que será necessária a Hegel a visão de um sistema social ordenado por meio de instituições sociais "garantidoras de liberdade antes do processo de tomada de decisões dos sujeitos isolados ou unidos" (2015, p. 112). Mais além, o autor detalha que: 
[...] em primeiro lugar deve estar esboçada a estrutura de instituições de reconhecimento nas quais os sujeitos possam alcançar sua liberdade social antes que essas instituições, em um segundo momento, possam ser postas no papel de tomar posição diante do ordenamento delineado. Resumidamente, o reconhecimento tem de preceder a liberdade da pessoa individualizada e a liberdade dos que deliberam entre si discursivamente. (2015, p. 113).

Com isso, é dado concluir que a figura de um "ordenamento ético" é formada por meio de uma reconstrução com a participação de sujeitos historicamente situados numa determinada realidade social. Em consequência, o complexo institucional de liberdade social não é tido como algo alcançado a partir de um projeto teórico previamente idealizado. A concepção de justiça em Hegel é, portanto, fruto de uma historicidade social concreta, a qual contrasta com as concepções teóricas fundamentadas em princípios/procedimentos gerais e abstratos. Nesse sentido, é possível concluir com Honneth que "a ideia de liberdade social de Hegel coincide com intuições pré-teóricas e experiências sociais em grau muito maior do que se poderia ter nas outras ideias de liberdade da modernidade" (2015, p.
115). Tal noção de liberdade é resultante da experiência espontânea entre o indivíduo e suas relações intersubjetivas, dentro de uma cadeia de reconhecimento e incentivos recíprocos, na promoção de fins subjetivos que se complementam socialmente. Conforme atenta Honneth, "Hegel conceituou essa experiência com sua formulação do 'estar consigo mesmo no outro'” (2015, pp. 115-116). O autor, por fim, refere-se a um "desnudamento histórico de classes de práticas normativas" como parte da apresentação teórica do conceito de liberdade de Hegel. Esse fenômeno se manifestaria pela satisfação mútua dos sujeitos na realização da liberdade individual num ambiente comunitário. Assim, por meio de diversas práticas consideradas conjuntamente, há a formação de instituições viabilizadoras do alcance de objetivos pela via de uma satisfação recíproca de interesses individuais.

Posto isso, sintetizando os aspectos da influência hegeliana na teoria desenvolvida por Honneth, afirma Pedersen:

Primeiro, a concepção padrão de autonomia focada na liberdade negativa ou reflexiva deve ser suplementada por uma concepção de liberdade social. Segundo, uma teoria da justiça não pode se restringir à esfera pública e política; [...]. Terceiro, uma teoria da justiça não pode se basear no construti- 
vismo kantiano mas deveria ao invés de empregar o que Honneth refere como reconstrução normativa." (tradução nossa). (LYSAKER; JACOBSEN, 2015, p. 237).

\section{A reconstrução normativa, os mode- los de liberdade e o papel das institui- ções sociais}

A via reconstrutiva promulgada pela matriz metodológica hegeliana possibilita a compreensão do ordenamento social como "uma estrutura institucionalizada de sistemas de ação" (HONNETH, 2015, p. 121). Em tal aspecto, o processo de reconstrução normativa correspondente deve se apoiar na apreensão dos valores impregnados na cultura e na ética relacionais - fundados em práticas sociais aceitas e em instituições já estabelecidas coletivamente -, os quais são realizados nas distintas esferas de ação na sociedade, buscando uma compreensão dos seus processos de formação e das respectivas normas comportamentais. Percebe-se, assim, uma estreita relação de codependência de uma ideia de justiça em referência aos valores éticos fundamentais observados socialmente. Acerca disso, vemos a seguinte explanação de Honneth:

[...] sem a fundamentação mediante uma ideia do bem, a exigência de nos comportarmos de maneira "justa" para com as outras pessoas nada significa, já que não podemos saber em que sentido lhes devemos o que é "delas", somente quando temos clareza da consideração ética pelo outro em nosso agir comum podemos dispor sobre o ponto de vista que transmite os padrões necessários para um fazer e um permitir juntos. (2015, p. 122).

Já no que se refere às diferentes interpretações que concorrem entre si acerca da constituição da liberdade individual - em meio a uma diversidade de "concepções nucleares" -, para se tornarem responsáveis pela formação de estruturas institucionais, afirma o autor não ser possível assumir uma transmutação dos valores da liberdade nas diversas formas institucionais e suas funções. Tal feito apenas se efetivaria por meio de uma materialização de tais valores, em toda sua diversidade de interpretações, no seio das esferas de ação institucional (2015, p. 123).

Para melhor ilustrar sua argumentação, Honneth apresenta, então, um estudo minucioso dos diferentes modelos de liberdade na modernidade, a saber: a) liberdade negativa; b) liberdade reflexiva; e c) liberdade social. Pela ideia de liberdade negativa, parte-se apenas de uma garantia jurídica de não interferência nas eventuais ações individuais escolhidas pelo sujeito, dotado de auto- 
determinação. A liberdade reflexiva, por sua vez, é encarada como resultado de uma ação intelectual produzida pelo sujeito enquanto capaz de decidir acerca do melhor a ser executado numa determinada circunstância. Todavia, apenas com a liberdade social haveria a participação de fatores sociais relacionados às interações intersubjetivas, efetuadas mediante as vias institucionais viabilizadoras da cooperação entre os sujeitos para a satisfação de seus fins respectivos.

O caráter mediador das instituições é, portanto, essencial e sua função primordial é a de "manter os sujeitos informados de antemão sobre quais de seus objetivos estão entrecruzados" (2015, p. 124). Nesse sentido, o autor faz questão de ressaltar a importância da vinculação da liberdade à sua efetiva realização mediante as instituições sociais, as quais são envolvidas numa relação de condicionalidade necessária para o modelo da liberdade social. Assim, explica Honneth que "[...] a teoria não deve se limitar à derivação de princípios formais, mas deve abranger a realidade social, pois só nela existem as condições sob as quais o objetivo, por ela buscado, de prover a todos a maior liberdade possível pode acontecer." (2015, pp. 124-125). Adiante, afirma que:

[...] é a referência ética à ideia de liberdade, necessária para que uma teoria da justiça deixe os contextos puramente for- mais e ultrapasse as fronteiras para a matéria social; ora, elucidar o que significa para os indivíduos dispor de liberdade individual implica, necessariamente, nomear as instituições nas quais ele [...] pode regular a experiência do reconhecimento. (2015, p. 125).

Diante disso, o autor vai destacar a necessidade de que haja um desdobramento em direção a que as sociedades liberal-democratas na atualidade sofram um processo de "preparação gradual" das suas esferas de ação. De tal modo, é colocado que "o valor de liberdade de modo algum foi tomado de forma institucional e específica, típica de uma função" (2015, p. 125). Como decorrência, Honneth defende que se proceda a uma diferenciação clara das distintas interpretações de liberdade surgidas ao longo da história, bem como de seus respectivos complexos de ação institucional, de modo a perceber-se que, enquanto nas esferas relativas aos dois modelos iniciais de liberdade são constituídos os meios de conhecimento e de aceitação intersubjetiva, apenas no terceiro modelo de liberdade (social) há uma efetiva disponibilização de esferas de ação responsáveis por formas distintas de comunicação conjunta entre os sujeitos. Nesse contexto, grande parte da fundamentação responsável pela liberdade social estará situada nas esferas sociais per- 
meadas por práticas, costumes e papéis desempenhados socialmente, em detrimento de normas jurídicas. Verifica-se, então, que a evolução reconstrutiva é diretamente proporcional a um distanciamento do aspecto jurídico formal da liberdade negativa. Com isso é dado concluir, com o autor, que "[...] as condições de justiça podem ser dadas não apenas sob a forma de direitos positivos, mas também sob a forma de atitudes, modos de tratamento e rotinas de comportamento razoáveis." (2015, p. 127).

Nesse sentido, a abordagem reconstrutiva honnethiana é descrita por Claassen como sendo processada mediante quatro premissas:

A primeira premissa é a de que toda sociedade reproduz a si mesma aderindo a certos valores fundamentais (RF 18-19). A ordem existente sempre tem que se fazer aceitável para os seus membros pela legitimação de certos valores éticos [...]. A segunda premissa expressa que uma teoria da justiça deveria identificar aqueles valores ou ideais, os quais são essenciais para a reprodução social (RF 20). [...] A terceira premissa expressa que isso requer uma análise social que reconstrói a realidade social até o ponto de identificar quais práticas e instituições podem contribuir para os valores sociais anteriormente identificados. [...] A quarta premissa expressa que isso envolve criticar a realidade existente onde ela falha em efetivar seu potencial para realizar esses valores em toda a sua extensão (RF 27-28). (tradução nossa). (CLAASSEN, 2014, p. 67).

Assim, Honneth aponta que as liberdades referidas são muito mais dependentes de um sistema entrelaçado de práticas e costumes socialmente institucionalizados e confirmados na experiência concreta, do que de categorias jurídico-estatais. E que, embora sejam de difícil determinação, não podem jamais ser omitidas de uma teoria de justiça.

\section{A liberdade jurídica: prerrogativas e limites. Os direitos individuais, so- ciais e políticos}

Desde o afloramento das sociedades liberais modernas é reconhecida a necessidade de direitos subjetivos e de limites à ação do Estado para que os indivíduos possam colocar em prática suas determinações como agentes livres. Segundo Honneth, observa-se que tal concepção permaneceu praticamente imutável ao longo do tempo, sendo que o maior impacto foi obtido pela amplitude de alcance dos direitos subjetivos, tendo em vista que, "mediante a pres- 
são de movimentos sociais e argumentos político-morais [...], adicionam-se ainda novas categorias pensadas como complementares" (HONNETH, 2015, pp. 128-129). Ao longo do processo histórico, as conquistas viabilizadas pela democracia proporcionaram uma nova fonte de legitimação na criação de direitos, podendo os cidadãos se reconhecerem como autores e destinatários das normas jurídicas estatais. Todavia, percebe-se aí uma assimetria entre a destinação puramente privada dos direitos outorgados e a deficiência de instâncias/espaços de interação social propícios à concretização desses direitos. A partir disso, para o autor, evidencia-se a proposta de uma partição conceitual do sistema normativo estatal, considerando-se que, nas sociedades modernas, "o ordenamento jurídico [...] deve ser dividido em duas esferas garantidoras de liberdade, que, com base nas diferenças em sua arquitetônica e infraestrutura, podem configurar dois polos de nossa busca por uma reconstrução normativa da eticidade democrática." (2015, p. 130).

Nessa tarefa reconstrutiva, proposta por Honneth, há um primeiro espaço, de garantia da autonomia privada, com o resguardo dos direitos individuais que lhe são inerentes; e, num outro espaço, uma função dada ao sistema jurídico, voltada para a efetivação de uma "autonomia coletiva pela qual, em cooperação como sociedade civil, [cidadãos e cidadãs] deliberam sobre quais direi- tos deverão ser reciprocamente concedidos e como deverão ser implantados" (2015, p. 130). Ressalta-se que essa atuação exigida do sistema jurídico somente pode se dar no âmbito das esferas institucionais propiciadoras da liberdade social, inseridas dentro do complexo da "eticidade", tal como definido por Hegel.

Honneth, na compreensão do "sentido ético da liberdade jurídica", ao destacar seu papel de relevo no conceito de justiça social, vai enxergar a liberdade negativa como responsável pela ocultação dos direitos individuais, relegando-os a um exercício meramente privado da vontade subjetiva. Daí, verifica-se uma limitação decorrente da ausência de meios de interação social, os quais não podem ser oferecidos pela liberdade jurídica. $\mathrm{O}$ autor aponta, assim, para a incompletude da liberdade considerada apenas pelo viés dos direitos individuais, servindose inclusive como "tendência a minar e subverter a rede existente de relações sociais" (2015, p. 131). Nesse ponto, é afirmado que "formular a sua própria liberdade apenas sob a forma de reivindicação de direitos significa supor que os deveres, as vinculações e as expectativas informais e não jurídicas nada mais são que um bloqueio de sua própria subjetividade." (2015, p. 132).

A função do "direito abstrato", em Hegel, bem como dos demais direitos subjetivos, desdobra-se em duas facetas: a) forma de resolução finalística 
de conflitos, derivada da busca de proteção do interesse subjetivo pelo indivíduo, a fim de conseguir a satisfação eticamente formada da vontade; e b) espaço de atuação protegido ("manto protetor") para a potencial exploração, livre de censura, das dimensões de sua personalidade. Honneth analisa que, desde a sua concepção, os direitos subjetivos passaram a ser fortemente associados a uma orientação econômica, com expressão na liberdade contratual e no direito de propriedade. Posteriormente, filósofos como Marx principalmente, teceram fortes críticas a tais direitos, numa forma de ataque a sua utilização como instrumentos ideológicos de dominação das classes privilegiadas dentro do capitalismo. Todavia, com tal interpretação, perdem-se de vista outras maneiras de utilização dos referidos direitos. Honneth procura, então, sublinhar a interpretação reconstrutiva hegeliana sobre o tema, destacando a importância da função do direito de propriedade na interpretação hegeliana da ética dos direitos fundamentais nos moldes liberais. Nesse sentido, observa que:

Para Hegel, o direito básico de todas as entidades (jurídicas) para dispor da propriedade privada não se fundava na necessidade de dispor dos meios de suas necessidades elementares; segundo ele não é o direito positivo que tem de zelar pelo "sustento" das pessoas, mas o mercado de trabalho e de produtos da sociedade burguesa, que satisfaz às suas próprias exigências somente à medida que assegura a sobrevivência econômica de seus partícipes. (2015, p. 133).

A função primordial do direito de propriedade seria, pois, garantir a satisfação da vontade individual por meio da posse de objetos exteriores legitimamente obtidos. Seria para Hegel a concessão de um direito com equivalência igual para todos os cidadãos, considerando que, "para que a sua 'vontade livre' possa se tornar uma 'vontade efetiva', ao sujeito deve corresponder um direito [...] de ter uma série indeterminada de objetos à sua exclusiva disposição" (2015, pp. 134135). Acerca desse equilíbrio entre a "vontade livre", "vontade subjetiva" e sua correspondente efetivação, aponta Honneth para a necessidade de conferir ao sujeito o direito fundamental de disposição privada sobre objetos exteriores, como um modo de salvaguardá-lo da abstração do formalismo jurídiconormativo, conferindo-lhe a possibilidade de se reconhecer como personalidade individual dotada de vontade (2015, p. 135). Cabe observar, entretanto, que Honneth considera não ter Hegel esclarecido satisfatoriamente quais os constituintes objetivos que possibilitam o reconhecimento da indi- 
vidualidade da "vontade livre" na aquisição privada de objetos exteriores.

No que se refere à concepção de direitos dos teóricos liberais, e à assim chamada primeira geração de direitos, estes simbolizam a proteção normativa a uma autorrelação privada puramente individual. Posteriormente, surgiu a controvérsia acerca de como seria feita a relação dos direitos de participação política com os direitos sociais. Nesse ponto, Honneth afirma serem pouco relevantes indagações acerca das "circunstâncias históricas e pela sucessão temporal do estabelecimento daquelas diferentes classes de direito" (2015, p. 142), para uma tarefa reconstrutiva das relações jurídicas nas sociedades modernas. $\mathrm{O}$ aspecto central a ser avaliado seria, assim, a forma global de conexão entre as distintas categorias de direitos na formação identitária da liberdade individual, proporcionada pelo direito positivo no âmbito da coletividade dos integrantes da sociedade. Para o autor, a conexão entre as distintas categorias de direitos deve ser realizada no plano conceitual. Dessa forma, explana que as liberdades jurídicas não podem ser entendidas como fundamento de compreensão/reconhecimento entre os sujeitos de direitos, sendo predominante neste tipo de liberdade o caráter essencialmente negativo dos direitos sociais, resultante "da tarefa de conferir aos indivíduos a possibilidade material de, com os direitos liberais, exercer a autonomia privada que lhes é garantida de modo eficaz" (2015, p. 142).

Por outro lado, pode-se inferir que as duas primeiras categorias de direitos (individuais e sociais) servem de proteção ao indivíduo nas esferas privada e material, enquanto a terceira categoria (direitos políticos) conduz a uma necessidade de cooperação intersubjetiva "ou ao menos, em intercâmbio com todos os demais partícipes do direito" (2015, p. 144). Honneth vai, então, reafirmar que as duas primeiras categorias de direitos são compreendidas e efetivadas na "construção de um eu privado", enquanto que a terceira categoria de direitos remete a uma evocação de cidadania cooperativa, na construção de uma "vontade comum". De tal modo, o grau de comprometimento dos indivíduos com a participação numa forma cooperativa de formação democrática de uma vontade comum será determinante para a realização concreta dos direitos políticos e da expressão da liberdade de associação/cooperação entre os cidadãos. Nesse ponto, Honneth vai ressaltar o caráter tipicamente prático de efetivação dos direitos políticos, uma vez que "o surtido normativo que se faz por meio deles só pode ser elucidado pela inclusão de todas as atividades e práticas sociais necessárias à sua realização comum." (2015, p. 146).

$\mathrm{Na}$ seção intitulada "Limites da liberdade jurídica”, Honneth se ocupa de uma demonstração detalhada das condições em que se encontram as "esferas 
de liberdade", nas quais a autonomia da vontade (privada) poderá ser efetivamente exercida. São denominados como "sistemas de ação" os espaços institucionais onde as ações intersubjetivas de reconhecimento da liberdade jurídica são passíveis de serem praticadas. Identificam-se, portanto, três níveis de posicionamento dos elementos de satisfação das esferas de liberdade. Num "nível fundamental", estariam situados os "sistemas institucionalizados" de cooperação e de reconhecimento recíproco relativamente a normas de alcance comum. Num segundo nível, há uma "recíproca atribuição de estatuto", consistente na previsão de comportamentos alheios e de uma expectativa de observância das normas comuns. Em terceiro lugar, figura um espaço de "sistemas de ação" responsável pela formação de competências e atitudes que integram a participação dos sujeitos nas "práticas constitutivas". A partir daí, Honneth apresenta, em forma de tópicos, um maior esclarecimento da visão hegeliana acerca das condições para a liberdade jurídica, a qual, visando a uma melhor compreensão, tomaremos a liberdade de transcrever mais extensamente:

(a) Hegel, em sua Filosofia do direito, viu o sistema do "direito abstrato" caracterizado por uma classe especial de práticas sociais, que se dá por uma aceitação geral da norma: "seja uma pessoa e respeite os demais como pessoa". [...] concentrouse sobretudo no caso especial das transações econômicas, que é possibilitado pelo direito contratual. Se essa restrição posteriormente se fizer retroativa, revela-se que a institucionalização dos direitos subjetivos possibilita um tipo de interação social na qual os sujeitos estão abstraindo-se dos motivos e das orientações de valor pessoais, e por isso atuam mutuamente superando interesses puramente arbitrários [...].

(b) Desse modo, essa forma anônima de comunicação social só pode ser realizar porque os sujeitos participantes concedem-se reciprocamente o estatuto normativo, exercendo todas as ações sem que haja pressão de uma justificação no âmbito público compatível com o sistema dos direitos subjetivos: nas palavras de Hegel, eles se reconhecem reciprocamente como pessoas que têm o direito de decidir por si mesmas, no contexto das leis existentes, sobre quais os propósitos gostariam de perseguir [...].

(c) No processo de estabelecer essa relação de reconhecimento 
surge aquela forma especial de subjetividade que podemos chamar de "entidade jurídica". [...] As normas morais ou os princípios éticos considerados separadamente corretos devem ser mentalmente postos entre parênteses, se a coordenação de ação possibilitada pelo direito for bem-sucedida. No sentido inverso, também se exige que o mesmo sujeito confie que sua contraparte esteja disposta a se ater de maneira autônoma às normas jurídicas: isso pressupõe um elevado grau de antecipação da confiança, do autodomínio e tolerância, já que as ações juridicamente legítimas de outras pessoas devem ser aceitas também quando se suspeitar que por trás delas houve atitudes divergentes das próprias convicções [...]. (2015, pp. 148-151).

Nessa dinâmica própria das relações jurídicas, o sujeito atua de modo isolado, dotado de objetivos estratégicos. Ao se deparar com outros, sua ação deve ser limitada reciprocamente, no intuito de exercer influência, "a fim de chegar a um acordo bem-sucedido na comunicação" (2015, p. 151). Nesse sentido, o autor afirma a incapacidade efetiva desse tipo de relação, defendendo assim que a autonomia privada apenas poderá ser viabilizada devida- mente caso se proceda a uma saída dos seus próprios fundamentos básicos. Isso se justifica, na medida em que um verdadeiro alcance ponderado dos objetivos de vida só se dá na direção de uma "confirmação real do bem, mediante uma atitude que se diferencie da do direito" (2015, p. 152). Para tanto, faz-se necessária a atribuição de motivações éticas dos sujeitos nas suas relações, seja pela "via do pensamento" ou pelo "contato real". Ainda no que concerne à liberdade jurídica e às liberdades garantidas aos sujeitos para o exercício da autonomia privada, Honneth explica que não se pode atribuir a tais requisitos, em si mesmos, serem constituintes de uma "insuficiência da liberdade jurídica". Todavia, o autor esclarece que a conduta assumida pelo agente inviabilizaria sua conexão com a diversidade de relações e responsabilidades entre os sujeitos sociais, por conseguinte, "enquanto planos de vida alternativos forem realizados de maneira apenas monológica, o indivíduo se encontrará num vácuo e, logo, num estado de quase completa indeterminação." (2015, p. 153).

Mais adiante, complementa que é preciso uma saída prévia do caráter de "entidade jurídica", para que se possa assumir um contato dialógico voltado para a concretização de objetivos de vida prática do sujeito, no qual "Os direitos vêm servir somente para questionar e revisar nossas ideias do bem, mas não para preparar e formular no- 
vas versões dela." (2015, pp. 153-154). Desse modo, sem um prévio abandono da esfera de liberdade jurídica, não poderemos ir à busca do alcance de objetivos de vida, os quais são dependentes das relações intersubjetivas/sociais estabelecidas no mundo real. Assim, conclui o autor não ser a liberdade jurídica, de modo algum, um espaço para o exercício da autorrealização individual. Ao passo em que ela viabiliza uma oportunidade para a reflexão do sujeito acerca dos seus projetos individuais e diretrizes pessoais, não é capaz de viabilizar concretamente "uma realização dos bens ou objetivos" (2015, p. 155). Honneth ressalta, então, o "caráter meramente negativo da liberdade jurídica", a qual é desprovida de meios para garantir a "conformação ética", a fim de que as decisões individuais possam ser implementadas na vida real. Portanto, é relevante esclarecer que os direitos subjetivos teriam seu valor dependente da existência de "precondições intersubjetivas" que, "de modo algum, podem ser produzidas por força de atitudes e posturas promovidas por eles" (2015, p. 156). Para concluir, sintetiza o autor que "o direito deve produzir uma forma de liberdade individual cujas condições de existência não podem ser produzidas, nem perpetuadas" (2015, p. 157), havendo a dependência de uma circunstância relacional de caráter unicamente negativo, "interrompida, com um contexto de prática ética que se alimenta, por sua vez, das intenções sociais de sujeitos não juridicamente cooperantes." (2015, p. 157).

\section{Liberdade moral: estrutura e condi- ções de realização}

A forma de instituição da concepção da liberdade moral se dá de um modo distinto do que acontece com a liberdade jurídica. Honneth consigna que, ao passo em que o estabelecimento dos direitos subjetivos viabilizadores da autonomia privada se dá de forma normativa, "a ideia de autonomia moral não está provida de um caráter vinculante controlável pelo Estado" (2015, p. 175). Por outro lado, observa que há, em ambas as formas de institucionalização, a materialização de práticas de reconhecimento recíproco. Assim, na liberdade moral, o sujeito realiza "um tipo especial de atribuição recíproca do estatuto normativo e cria-se a expectativa de uma forma específica da relação individual consigo-próprio" (2015, p. 175). Consequentemente, o autor assinala:

O princípio da autonomia moral, organizado também como sistema de ação, compartilha com a autonomia privada, garantida pelo sistema jurídico moderno, o caráter de possibilitar a liberdade, mas não de realizá-la no âmbito instituci- 
onal; pois aqui também é dada aos indivíduos a oportunidade, concedida culturalmente, mas não garantida pelo Estado, de se retrair por trás dos deveres de ação, a fim de, à luz de um ponto de vista especial - o da moral -, novamente estar em conexão com um mundo real outrora vivenciado como dividido. (2015, pp. 175-176).

Segundo Honneth, o desenvolvimento da ideia de autonomia moral em Kant dá-se mediante dois passos, cada qual contendo diferentes exigências e pressupostos. Em primeiro lugar, devese garantir que nossas ações sejam guiadas por fatores racionais, descontaminados de impulsos outros que possam afastar-nos da autodeterminação e da centralidade nas nossas próprias convicções. Em segundo lugar, há para Kant a condição inafastável de que o sujeito precisa ser a causa determinante do seu próprio agir. Ainda nesse aspecto, Honneth aponta que "Kant [...] cita a regra de ouro segundo a qual deve se tratar os outros unicamente como desejaríamos ou aspiraríamos ser tratados por eles." (2015, p. 178). Assim, Kant chega à formulação fundamental de que a liberdade está condicionada ao agir do sujeito em conformidade com a lei moral. Isso significa dizer que a ação livre está vinculada à orientação por motivos racionais, o que faz com que elas possam ser universalmente acei- tas. Nesse ponto, surge para Honneth a questão de saber se a ideia da liberdade individual, indissociável de uma "via de reflexão a uma posição moral da universalidade", detém em si algum tipo de valor ético. A filosofia moral kantiana propaga, assim, a possibilidade de recusa do indivíduo a situações em que a condição de universalidade moral não esteja atendida. Acerca disso, Honneth identifica um momento polêmico e crítico, pois avalia que a formulação moral kantiana não orienta a estruturação de vida do indivíduo nem de suas condutas, mas opera no sentido de promover o questionamento da juridicidade das nossas ações. Mais adiante, afirma que Kant expressava, de forma enfática, não poder o exercício da liberdade moral estar associado a pré-condições do tipo psicológicas ou sociais, tendo em vista que "a recorrência ao princípio da universalidade ou, como ele refere, ao imperativo categórico' é algo que em nossas ponderações prático-morais possui certa coação 'transcendental'” (2015, p. 180).

$\mathrm{O}$ autor chega, portanto, à conclusão de que a autonomia moral kantiana é revestida por um caráter negativo, decorrente da disponibilidade garantida ao indivíduo de recusar todas e quaisquer "imposições sociais ou circunstâncias que não passem pela prova subjetiva da universalidade social" (2015, p. 181). A tese kantiana de autolegislação é entendida como o dever de agir conforme o atendimento a leis gerais, 
em que "todo e qualquer sujeito é reconhecido como um fim em si e, por isso, como pessoa moral" (2015, p. 184). Honneth vai atentar, outrossim, para a existência contemporânea de distintas versões de interpretação da formulação kantiana, todavia identifica nelas a abstração da necessidade de integração das condições socioculturais como pressupostos à integração da moral, pois "precedem a todo ato de autolegislação individual" (2015, p. 184). Nesse sentido, defende a inadequação de uma tal concepção de liberdade frente à estrutura das sociedades modernas, por se limitar ao papel de autolegislação do indivíduo, e postular uma visão social demasiadamente estreita:

[... tal como no caso da ideia de liberdade jurídica, também a concepção de liberdade que assim se delineia já não pode ser imaginada a partir da estrutura institucional das sociedades modernas: aos sujeitos, ela não apenas proporciona a autoconcepção para que possam recusar as relações existentes como "irracionais" [...]. O indivíduo que já antes, e em razão de suas concepções morais, ainda estava atrelado à eticidade concreta de sua vida real, para tanto, está autorizado na figura de pensamento da autolegislação moral em nome da liberdade, a fim de se transfe- rir para uma perspectiva a partir da qual ele tanto pode se opor de maneira crítica a normas existentes como pode intervir de maneira construtiva em favor de nossos sistemas de normas. (2015, pp. 191-192).

Conforme explana Honneth, a liberdade moral vai abarcar os espaços sociais não alcançados pelas normas do "legislador político", as quais possuem caráter vinculativo/obrigatório. Assim, "onde nenhuma lei jurídica nos obriga a este ou àquele comportamento, devemos ser 'livres' no sentido de devermos nos comportar somente com base em princípios que nos apareçam como racionais" (2015, p. 193). O caráter marcadamente ético desta liberdade se faz presente na orientação das relações não disciplinadas pela vinculação normativa das regras estatais, sendo caracterizada por sanções informais da natureza cultural. O autor vai identificar aqui, tal como no sistema de liberdade jurídica, a prevalência de três condições, cada qual dotada de limitações e de restrições que lhe são inerentes. Na primeira condição, destacase o papel da "autonomia moral", caracterizada pela ação livre do sujeito de tomar as posições que lhe pareçam moralmente mais adequadas nas interações sociais. Há, assim, um ambiente social de concessões recíprocas entre os sujeitos acerca das convicções morais alheias, o que é definido como 
"liberdade de autolegislação". O autor distingue, portanto, do conceito de "liberdade jurídica", pois o "exercício da liberdade moral está atrelado à disposição recíproca para a demanda em justificar intersubjetivamente as próprias decisões e defendê-las com argumentos comprováveis" (2015, p. 195). Nesse âmbito, é ainda importante que o sujeito, ao colocarem-se diretrizes próprias de ação, tenha a disposição para justificá-las como universalmente aceitáveis, no contexto das relações sociais. Numa segunda condição, parte-se do pressuposto da necessidade de justificação universal da ação do indivíduo perante todos os agentes sociais para a validade do alcance de um "respeito moral". Tal componente manifesta-se como uma forma peculiar de reconhecimento recíproco e teria como função "fazer coincidir o respeito pelo indivíduo [...] com sua inclusão na comunidade de todas as pessoas, e isso significa que deve fazer coincidir individualidade e comunalidade" (2015, p. 196). Em síntese, isso significa afirmar a simultaneidade do dever de justificação universal das diretrizes de ação individual, caso necessário, e do direito conferido ao sujeito de "articular em suas ações somente os princípios que considerar corretos" (2015, p. 197).

Por último, Honneth considera que a "institucionalização cultural" das relações de intersubjetividade recíproca acima descritas leva a uma forma de subjetividade denominada "moral". Nesse contexto, serão exigidos do agente não apenas aquilo que o autor denomina "capacidades autorrelacionais", mas ainda as chamadas "capacidades de orientação social", ambas necessárias a fazer surgir um sujeito dotado do potencial de exercer a liberdade moral. Assim, explana Honneth que a orientação do agir individual por princípios gerais deve pressupor a capacidade de se posicionar na perspectiva dos sujeitos relacionados aos efeitos da ação. Nesse aspecto, enfatiza que a capacidade de agir desse modo "[...] pertence igualmente ao rol de competências elementares, que devem ser atribuídas a um sujeito para que ele surja socialmente como representante da liberdade moral." (2015, p. 198).

Nesse contexto, o sujeito deve chegar a um ponto de reflexividade moral em que seja capaz de se assegurar "de maneira medianamente neutra do assentimento universal de seus possíveis princípios" (2015, p. 199). O autor vai se referir aqui a uma integração das normas de ação coletiva pelo indivíduo em que não fosse mais necessário remeter - se a um entendimento prévio relativo às "circunstâncias e normas institucionais". As suas ações teriam motivações fundadas unicamente num "assentimento virtual, informal e imparcial", relativo aos demais integrantes do meio social, com relação ao caráter de correção da própria conduta.

No que concerne ao processo de de- 
liberação moral dos indivíduos, Honneth destaca a impossibilidade de o sujeito se colocar numa posição de completa equidistância e neutralidade, a fim de expandir um assentimento universal. Em relação a isso, é justificado que "nossas próprias expressões linguísticas, dependentes de um uso comunicativo e, por isso, saturadas de nossas experiências históricas, estão a selar nosso distanciamento" (2015, p. 200). Assim, com relação à possibilidade de uma visão imparcial e de generalização da ação moral, é afirmado que, "[n]o contexto da liberdade moral, a imparcialidade ou a capacidade de generalização não podem significar uma a - historicidade, como eventualmente pode parecer em Kant" (2015, p. 200). Desse modo, compreende-se que a busca refletida por uma maior imparcialidade e universalidade possível esbarra na imersão do sujeito em regras e contextos normativos que orientam a própria participação dos indivíduos na sociedade e o desempenho dos respectivos papéis sociais.

Honneth situa a "liberdade moral" inserida dentro de um sistema de ação no qual os indivíduos sejam capazes de justificar os motivos que norteiam suas ações, em meio à abrangência de fatores e condições relevantes, numa perspectiva de convívio social e interação recíproca. Para o autor, a autonomia moral reciprocamente atribuída entre os sujeitos sociais trata-se de uma "técnica cultural”, indispensável para a resolu- ção de conflitos sociais cotidianos não passíveis de normatização legal. Para delimitar os limites inerentes à liberdade moral, Honneth opera a diferenciação de dois níveis de abstração. No primeiro nível, o indivíduo vai se posicionar numa perspectiva comum aos demais sujeitos autonomamente considerados, todavia o resultado de tal prática "não deve ser confundido com a exigência de assumirmos um ponto de vista despersonalizado ou completamente livre de emoções diante do nosso ambiente social" (2015, p. 202). Nesse sentido, o autor enfatiza a distinção entre imparcialidade e despersonalização, pois naquela a ausência de priorização de questões pessoais na resolução de conflitos morais não exige que "nos tornemos embotados e anestesiados ante os laços privados ou relações sociais" (2015, p. 202). No que se refere ao segundo nível de abstração dentro da liberdade moral, Honneth o identifica como decorrente da tradição kantiana, e implica que o sujeito possa, além de efetuar um distanciamento de seus interesses pessoais, vir também a desconsiderar as implicações formadoras de significados derivadas dos conteúdos absorvidos na vida das relações sociais. Nesse sentido, verifica-se uma distinção fundamental entre os dois níveis de abstração, conforme aponta o autor, pois no primeiro não é dado ao sujeito priorizar de maneira imediata as relações pré-existentes na resolução de conflitos, "enquanto no segundo caso deve- 
mos ainda ignorar o que significa manter e cultivar relações desse tipo" (2015, p. 203). O autor vai aludir, nesse ponto, à crítica feita por Hegel em relação à filosofia moral kantiana. Segundo Hegel, as máximas de ação definidas por Kant só podem ter lugar em meio aos condicionantes presentes no convívio social. Assim, aponta Honneth que a atenção às máximas de direção moral formuladas por Kant só tem espaço em meio às circunstâncias já vividas no âmbito social; tendo em vista que, na observação do imperativo categórico, "nos deparamos de algum modo com normas constitutivas de nossa respectiva forma de sociedade, que não podemos conceber como autorizadas por nós próprios, já que devemos primeiramente aceitálas como fatos institucionais." (2015, pp. 205-206). Dessa forma, alude à objeção de Hegel a uma espécie de autonomia moral nos moldes kantianos, visto não ser possível uma completa independência autorreferencial dos princípios da ação individual (subjetiva). Conforme o autor, há sempre a necessidade de que nossos juízos e ações morais se apoiem num "reconhecimento recíproco de fatos institucionais, que assumem a conformação de normas socialmente fundamentais de nossa forma de convívio" (2015, p. 206). Honneth observa ainda que os limites impostos a uma "autolegislação moral" se refletem nos limites da liberdade individual, também designada por liberdade moral. Tais limites são encontrados em regras sociais e não podem ser considerados como autoestabelecidos. Nesse sentido, aduz que "a todo discurso moral subjazem formas elementares de reconhecimento recíproco que são constitutivas da sociedade que a circunda" (2015, p. 207). Segundo o autor, há uma "força transformadora" na liberdade moral, que está ausente na liberdade jurídica, pois naquela há um potencial de transformação social "à medida que sua referência de universalidade permita um questionamento público da interpretação das normas da vida real" (2015, p. 208). Neste sentido é que poderia ser constatado o valor superior da liberdade moral sobre a liberdade jurídica.

\section{A insuficiência limitadora das li- berdades jurídica e moral e a proemi- nência da liberdade social}

Honneth afirma que, dentre as três concepções da liberdade mais nitidamente reconhecidas, e que tiveram origem na modernidade, duas - liberdade negativa e liberdade reflexiva - "chegaram a ser realidade e forma social nesses dois sistemas de ação" (2015, p. 223), isso principalmente nas sociedades com maior grau de desenvolvimento do Ocidente. Avalia que, na instituição da liberdade jurídica, deve ser conferida aos sujeitos "a oportunidade controlada pelo Estado de direito, de suspender decisões éticas por determinado período, 
para que se possa realizar uma apreciação do próprio querer" (2015, p. 223). Já pela instituição da liberdade moral, é facultado ao sujeito rejeitar imposições externas de modo juridicamente justificado. Nesse aspecto, o autor ressalta a existência de uma relação "parasitária" de tais liberdades com as atividades da vida social "que não apenas já as precede sempre, como também devem, só a elas, seu verdadeiro direito de existir" (2015, p. 223). Ao contrário dos efeitos sociais limitados, produzidos no âmbito da liberdade individual, a "realidade da liberdade" seria constituída apenas no âmbito das práticas instersubjetivas socialmente compartilhadas. Tal realidade se dá, pois, em meio a uma relação de reconhecimento recíproco entre os sujeitos sociais envolvidos, num contexto completamente isento de coerções. Conforme já colocado, tal concepção de liberdade foi desenvolvida por Hegel e alguns de seus sucessores, e possui várias repercussões na vida social:

[...] a ideia de liberdade assim delineada chegou mesmo a se tornar a que exerceu a maior influência sobre a formação das regras constitucionais e do espírito de uma série de instituições modernas. Nem a ainda jovem instituição do laço de amor "romântico", nem o sistema de ação capitalista de mercado [...] podem ser entendidas de ma- neira adequada se analisadas recorrendo -se exclusivamente às categorias da liberdade jurídica ou da moral (2015, p. 225).

Honneth defende que a legitimação e a força social das instituições acima referidas devem-se à espécie de liberdade classificada por Hegel como "social" ou "objetiva". Contudo, afirma existir um desconhecimento histórico acerca de tais visões da liberdade nas sociedades modernas, vindo a prevalecerem, assim, ideias de liberdade individual caracterizadas por uma debilidade jurídica e moral, as quais determinaram a concepção institucional de fenômenos sociais como o matrimônio, a família ou o mercado. Nesse contexto, o autor propõe uma contraposição, partindo do delineamento dos conceitos e conexões entre "determinado tipo de sistemas de ação institucionalizados e a liberdade social" (2015, p. 225), com vistas a efetuar uma reconstrução normativa em conjunto com a liberdade moral. Assim, tanto os sistemas de ação da liberdade jurídica quanto da liberdade moral são regidos por padrões normativos de reconhecimento recíproco. Todavia, tais formas de ação não operam no mecanismo de realização teleológica da própria ação em si mesma, tendo uma atuação limitada a um posicionamento reflexivo que consiste em "fazer uma revisão distanciada, ou de se autodefinir com respeito" (2015, p. 226). De tal forma, Honneth atribui ao pa- 
pel do reconhecimento recíproco uma "condição indispensável para realizar os próprios objetivos da ação" (2015, p. 226). Nesse sentido, é destacado que:

\begin{abstract}
A ação de um dos indivíduos está de certo modo incompleta, enquanto o outro ator não tiver elaborado a norma de modo correspondente, com a qual se comprometeram implícita e anteriormente em reconhecimento recíproco. A concepção recíproca de um estatuto normativo, que constitui a substância de todas as relações de reconhecimento, possui, nesse segundo caso, outro caráter que não o dos sistemas de ação previamente descritos. (2015, p. 226).
\end{abstract}

No caso das ações puramente individuais há uma "consideração normativa" que habilita apenas uma formulação da intenção subjetiva de modo desobstruído e autodeterminado. Já nas ações reguladas por um reconhecimento recíproco, os indivíduos vivenciam um entrelaçamento de intenções "de modo que elas só podem ser formuladas e executadas de maneira sensata sob a expectativa da respectiva consideração" (2015, p. 227). Esses sistemas de ação são descritos como "relacionais" e "éticos", considerando a complementação recíproca das atividades desenvolvidas, por um lado; e a inexistência de um mero dever obrigacional, mas de consideração moral, por outro. Nesse contexto, as expectativas de comportamento geradas no âmbito dos sistemas relacionais são revestidas do caráter de papéis sociais. Assim, o autor afirma que há uma complementariedade na realização dos respectivos papéis individuais nas "execuções de ação em si inconclusas, de modo que apenas coletivamente produzem a ação conjunta ou a unidade de ação prevista por todos os participantes" (2015, p. 227 - 228).

Nesse ponto, é importante a observação feita por Zurn de que Honneth não relega a um plano inferior ou desconsidera o papel das duas primeiras formas de liberdade tratadas:

É importante perceber aqui que Honneth não está negando nem a realidade nem a importância normativa da liberdade nas condições colhidas pelos modelos negativo e reflexivo. Indivíduos modernos valoram corretamente a capacidade de serem aptos a recuar, desistir de, obrigações e papéis sociais que se achem enredados. Às vezes, valoramos aquele espaço simples, sem obstáculos, para realizar nossos desejos contingentes que a liberdade negativa possibilita. Em outras vezes, a liberdade reflexiva é crucial para que um indivíduo possa dar um passo 
atrás em suas expectativas sociais, e avaliar a validade e utilidade daquelas expectativas à luz do seu próprio senso de moralidade e integridade pessoais. (tradução nossa). (ZURN, 2015, p. 161).

Por outro lado, Honneth observa que as esferas de liberdade social só são completadas quando os participantes da relação possam exercitar um consentimento reflexivo, pois, "[s]e obrigações desse tipo fossem impostas socialmente ou forçadas, os sujeitos não poderiam reconhecer na complementariedade recíproca de suas ações uma realização 'objetiva' de sua própria liberdade, desejada e aspirada de dentro pra fora" (2015, p. 228). Nesse aspecto, revela-se a influência hegeliana, que na Filosofia do Direito já afirmava que, nos sistemas de ação e da moral, deveria se garantir aos sujeitos a possibilidade de revisar as vinculações e obrigações nas quais se encontravam envolvidos. Diante disso, Honneth considera que a "gramática moral", decorrente das diversas ações e papéis sociais desempenhados pelos membros da sociedade, pode ser associada a uma "reconstrução normativa", na função de retratar a completude das esferas de ação das sociedades atuais. Condiciona-se, portanto, a efetivação da "realidade da liberdade" a uma reconstrução das esferas de ação na direção de um reconhecimento como pressuposto para o alcance dos fins a que se prestam os papéis desempenhados pelos sujeitos em meio a obrigações caracterizadas como complementares e recíprocas. Então, Honneth efetua uma diferenciação das esferas institucionais em três níveis distintos de práticas sociais, a saber: a) esfera institucional das relações pessoais; b) esfera institucional de ação nas economias de mercado; e c) esfera institucional de abertura política (2015, p. 232). Dentro de cada um desses sistemas, deverá ser efetivado o "padrão do reconhecimento recíproco e das obrigações complementares" (2015, p. 232) que servirá como fundamento para a realização de diferentes formas de liberdade social. O autor ressalta que, na tarefa reconstrutiva das "regras de ação normativa", nem sempre haverá uma correspondência com as práticas cotidianas dos sujeitos sociais, havendo espaço para determinados "desvios individuais desses padrões de ação resumidos como 'tipicamente ideais', que se comprovam altamente característicos para determinadas tendências de nosso tempo" (2015, pp. 232 - 233). Afirma ainda que as diferenças de ação individual dentro de um sistema de ação específico devem ser vistas como "anomalias sociais", resultantes do fracasso na realização da liberdade social. Nesse sentido, esclarece que as situações patológicas provenientes da liberdade jurídica e/ou da liberdade moral são fruto de erros interpretativos, de algum modo influenciados por regras 
de ação, ressaltando que "as práticas normativas em ambas as esferas são em si incompletas, demandando complementação por relações da vida real, no entanto, sem que isso se torne aparente no desempenho dessas práticas" (2015, p. 233).

O autor atesta o caráter pretensamente autárquico das esferas éticas, pois o exercício das suas próprias regras de constituição não seria dependente da sua natureza em si, havendo um aperfeiçoamento "somente mediante reconexão na vida real" $(2015,233$ 234). Zurn define tal formulação levada a efeito por Honneth, com respeito às esferas sociais, nos seguintes termos:

[...] Honneth lida em detalhes não apenas com seus princípios normativos de legitimidade subjacentes, mas também com os modos nos quais cada uma exibiu certas limitações, desenvolvimentos incorretos, injustiças, ou mesmo patologias. Em outras palavras, a reconstrução das esferas sociais é pretendida como uma contribuição a uma teoria crítica do presente: uma teoria interdisciplinar da sociedade com intento emancipatório. Nesse sentido realizando uma teoria da justiça por meio de uma análise social, Honneth pretende simultaneamente exibir a realidade de instituiões justas, seus princípios inerentes de justificação normativa, e a sua crítica concreta à luz desses mesmos princípios. (tradução nossa). (ZURN, 2015, p. 166).

\section{A liberdade social e suas manifes- tações nas relações pessoais: amizade, relações íntimas e família}

O autor procura demonstrar as distinções entre os sistemas sociais já mencionados (relações pessoais, economia, e da participação político-pública) em seus diversos aspectos. Em primeiro lugar, situa a forma de institucionalização, que poderá ser contratual ou não contratual. Assim, nas relações pessoais e na participação política, seria predominante a forma não contratual das obrigações assumidas, "enquanto nos sistemas estabelecidos do agir mediado pelo mercado prevalecem as obrigações em forma de contrato" (2015, p. 235). Em segundo lugar, e com grau maior de importância estariam as relações nas quais os fins individuais teriam sua realização condicionada a um "entrelaçamento" de papéis subjetivos. Por meio de tais distinções, Honneth entende ser possível dar início a uma tarefa de reconstrução normativa "precisamente no ponto em que o aspecto ontogenético reúne as primeiras experiências de liberdade social, a saber, na esfera das relações sociais" (2015, p. 236). 
Conforme expõe Honneth, já há mais de dois séculos que o campo das relações pessoais é considerado como o lugar de uma forma de realização peculiar de liberdade. O autor menciona as distintas maneiras como pensadores tais como Schiller, Hegel, Schleiermacher e Kierkegaard procuraram refletir sobre a interação e a familiaridade decorrentes das relações entre dois indivíduos se traduzirem numa efetivação especial de liberdade. As considerações literárias e filosóficas seriam, entretanto, "apenas um pálido reflexo das profundas transformações que no mesmo período sucederam nas relações intrínsecas à vida real" (2015, p. 237). Verifica-se, portanto, um gradual processo de liberação da ligação entre as relações sociais e as formas de associação social baseadas nos interesses econômicos em direção a experiências emocionais, "nas quais um pode contemplar no outro a oportunidade e a condição de sua autorrealização" (2015, p. 237). Desse modo, Honneth atesta que "Relações pessoais são, assim o quer a sociedade moderna, relações sociais em meio ao anonimato e ao desenraizamento nas quais a natureza interior do homem se encontra mediante a confirmação recíproca de sua liberdade" (2015, p. 238).

A institucionalização das novas formações sociais, ao longo do tempo, foi constituindo redes de estabilidade quanto à confiança e expectativas de comportamentos recíprocos. Tais re- lações vêm sofrendo constantes transmutações na sua delimitação, e protagonismo nos desempenhos dos papéis subjetivos recíprocos; todavia, conforme pontua o autor, nos diversos modelos relacionais estabelecidos, há a possibilidade de ajustes entre as obrigações de papéis complementares, a fim de oportunizar aos participantes a realização de "qualidades que considerem essenciais por meio de confirmação, apoio e auxílio recíprocos" (2015, p. 239). Honneth defende que quanto menor for o grau de coação externa e de "missões sociais", maiores serão as possibilidades para o protagonismo emocional dos participantes e articulação dos seus estados emocionais subjetivos. Segundo o autor, ao longo de dois séculos, as transformações ocorridas no campo das relações pessoais e nas suas instituições formadoras não ficam atrás das mutações ocorridas no campo das relações econômicas e socioestruturais. O autor propõe, então, uma reconstrução normativa baseada nas novas modalidades institucionais atuantes nos elementos constitutivos das relações sociais, caracterizando-as como a primeira esfera de liberdade social. A partir daí, segue-se um estudo histórico-evolutivo e sociológico das formas sociais consideradas nucleares na compreensão da liberdade social, a saber: a) amizade; b) relações íntimas; e c) família.

a) Amizade:

As normas que regem as rela- 
ções de amizade são "socialmente institucionalizadas", havendo um compartilhamento coletivo das práticas adequadas aos envolvidos na relação. Em caso de desvios/violações aos regramentos implícitos, atesta o autor, geralmente é possível verificar-se o surgimento de uma crise e, até mesmo, de rompimentos na relação de amizade.

Antes limitada a indivíduos pertencentes a uma mesma camada/classe social, bem como por barreiras impostas pelo sexo ou pela faixa etária, houve, a partir da segunda metade do século XX, uma transformação que elevou a amizade para além dos limites tradicionalmente existentes. Conforme Honneth, afora os deveres e regras que estabelecem obrigações recíprocas de atenção, apoio e confiança na vida diária, conforme já havia tratado Aristóteles, as relações modernas de amizade trazem uma nova caracterização que consiste em "fazer do querer próprio algo que possa ser experimentado por uma pessoa, e sua articulação, por sua vez, aspira ao outro concreto" (2015, p. 252). Com isso, procura-se esclarecer a existência de papéis obrigacionais que possibilitam aos indivíduos manifestarem sentimentos e condutas que dependem do outro para sua apresentação e concretização. Conforme aponta o autor, há na amizade um entrelaçamento de papéis e obrigações recíprocas, fruto do desejo mútuo de manifestação de sentimentos e atitudes, "de tal forma que ambas as partes têm confiança e certeza de que com os desejos mais idiossincráticos ou despropositados, haverá consideração e não traição" (2015, p. 252). É, pois, por tais razões experienciais e autoarticuladoras que o autor afirma que a amizade se converte em "domicílio da liberdade social". Não haveria como se duvidar, portanto, da importância institucional moderna da amizade, defendendo Honneth mesmo sua supremacia frente aos fenômenos contemporâneos do individualismo e de flexibilização das demais formas de relações sociais.

\section{b) Relações íntimas:}

Atualmente, é possível verificar-se uma profunda transformação no papel das relações íntimas, ao ponto em que elas se encontram dissociadas do casamento e da família. Sua prática é vista hoje como legítima, a despeito de não existir a vontade de uma ligação duradoura, e tal condição dispõe de reconhecimento estatal. Honneth traça um marco genealógico comum entre a amizade moderna e o desenvolvimento institucional das relações íntimas, as quais remontariam ao final do século XVIII. Ao longo de tal período em diante, seria verificada uma transformação que afeta a noção de sexualidade e das relações entre pessoas de sexos diferentes, a qual "passa a ser associada a uma transformação também na arquitetura da liberdade individual" (2015, p. 259). Assim, nesse novo espaço de liberdade, caberia aos próprios indivíduos unicamente a escolha da relação íntima, havendo o 
reconhecimento social de sua consumação. O autor situa o século XX como o período de transformação no qual é possível observar a institucionalização desse modelo de relação, todavia ainda carecendo de normatização prática. Expõe, assim, a problemática relativa aos traços caracterizadores da relação, bem como a definição de papéis dos envolvidos:

[...] a relação sexual está liberta das amarras dos cálculos de utilidade dos pais e aos parceiros ficam apenas as considerações de ordem sentimental dos noivos - contudo, oficialmente, no contexto jurídico do casamento estavam previstas e a ele se associavam apenas práticas heterossexuais. No seio do matrimônio doravante pensado como "livre", se pela norma prevalece o fundamento da igualdade entre homem e mulher, superficialmente a vigência das imagens de papéis tradicionais e do poder masculino asseguram que as tarefas domésticas continuam a ser distribuídas de maneira altamente desigual. (2015, pp. 260-261).

Tomando como apoio a institucionalização do amor romântico, a partir do século XX, há um maior desenvolvimento na democratização do instituto das relações íntimas em direção ao pa- pel das mulheres e à inclusão de minorias sexuais. Passou a ser tolerada publicamente a prática de relações íntimas entre pessoas do mesmo sexo, e houve a definitiva equiparação jurídica entre homens e mulheres, com a integração destas ao mercado de trabalho. Em paralelo a tais processos, elenca Honneth a flexibilização do divórcio, o fim do tabu sexual fora do casamento, e o respeito aos direitos das crianças, com a progressiva eliminação dos castigos físicos.

O autor observa, então, que as relações íntimas, no contexto das sociedades ocidentais da atualidade, efetivam "uma possibilidade autônoma de vínculo pessoal” (2015, p. 264). Ressalta também o papel da liberdade de escolha do parceiro a quem se vinculam os sujeitos intimamente, e chama atenção para a necessidade de sujeição às normas incidentes na concretude das obrigações recíprocas, de modo a viabilizar uma espécie de liberdade social. Honneth atenta, nesse contexto, para os reflexos problemáticos ligados à sobrevalorização do sucesso profissional e da excessiva individualidade dos interesses pessoais, chegando a falar numa crise na realização das obrigações e papéis dentro das atuais relações íntimas. Assim, alerta para as dificuldades impostas pela dinâmica do mercado de trabalho atual e pela interferência da ética do mercado capitalista em geral no cumprimento dos deveres de assistência física e emocional dos sujeitos da 
relação, tendo em vista a incapacidade vivenciada na formação de vínculos duradouros e desinteressados, colocando em cheque os elementos de amor e cuidado necessários a uma relação íntima como forma de liberdade social.

\section{c) Família:}

Honneth procede a um estudo detalhado acerca do surgimento da família moderna, procurando demonstrar as constantes transformações e as diversas formas de manifestação da entidade familiar na sociedade, ao longo do tempo. O autor afirma que a complexidade das relações matrimoniais e de parentesco chegou a sua culminância na chamada "família burguesa", tratada por autores como Hegel e Schleiermacher como centro de realização da liberdade social. Honneth explica que a concepção de liberdade e de realização advinda das relações de tal formação da entidade familiar iria perdurar por, ao menos, um século e meio. Os abalos sofridos por esse modelo foram sentidos ao longo do séc. XIX, sendo retratados em conhecidas obras ficcionais, por autores de diversos países na literatura europeia. Destaca, nesse contexto, a contestação feminina ao papel de dominação do homem no núcleo familiar e à moral completamente inferiorizante à condição da mulher nas relações.

Nos anos 1960, estudiosos sociais como Parsons já anunciavam uma progressiva transformação no interior das relações familiares, envolvendo fatores como a divisão de tarefas na educação dos filhos e a predominância do caráter emocional das relações entre os membros da família moderna. Honneth analisa que o alcance a que chegaram as transformações presenciadas nos últimos setenta anos dá-se notadamente pela igualdade intersubjetiva e pelo predomínio do uso de formas de negociação em detrimento da obediência hierárquica na educação dos filhos. Com isso, houve marcante mudança na interação familiar com relação ao papel dos filhos, os quais passaram a ter voz ativa, com uma atuação marcada cada vez mais por autonomia ao invés de subjugação. Outro fator, destacado como decisivo na mudança de relações de poder entre marido e esposa, seria a participação consolidada das mulheres no mercado de trabalho, sendo isso responsável por uma mudança marcante na simetria dos papéis entre o casal, caracterizada pela ausência de coerções e pela atuação de ambos no sustento da família (2015, p. 293). A divisão de tarefas assume, pois, um caráter de parceria, na qual os pais encontram-se em igualdade de condições no cumprimento de direitos e obrigações familiares e na educação dos filhos. Desse modo, conforme Honneth, há o surgimento de uma nova concepção de família.

De outro lado, o autor salienta a maior longevidade dos vínculos familiares em relação aos demais relacionamentos pessoais e que, a despeito 
da atual pluralidade de formações de relações familiares, há como resultado um aumento "quase paradoxal da triangularidade autoconsciente nas famílias modernas" (2015, p. 300). Passou a ser observada uma reciprocidade no dever de cuidado e de assistência, que se inverte a partir do envelhecimento dos pais, resultado do aumento da expectativa de vida na sociedade contemporânea. O direito à liberdade social associado à formação das relações familiares está, segundo Honneth, calcado na mutualidade do servir de seus membros nas diversas fases do ciclo vital de cada um deles, não se dando tal fenômeno em nenhuma das outras relações sociais. Afirma, então, que esse traço distintivo próprio da família acompanha o ritmo corpóreo da vida humana, num convívio que se expressa como "centro organizador da relação afetiva entre os membros" (2015, p. 313). Em tal aspecto, as características inerentes à intersubjetividade presenciada na relação familiar tornam possível um exercício em que os indivíduos são estimulados a se colocarem na condição uns dos outros, propiciando uma intercomunicação fluida entre os limites geracionais, fundamentada no caráter lúdico dessas interações.

Em seu diagnóstico das sociedades ocidentais contemporâneas, Honneth constata a ausência de um ambiente social e econômico em que as famílias possam garantir o alcance do tipo esperado de liberdade social. Seriam ne- cessárias, portanto, mudanças tanto na legislação trabalhista quanto nos sistemas de seguridade social que viabilizassem maior compensação econômica aos que se dedicam ao cuidado dos familiares na fase inicial da vida e na velhice. Por isso, o autor defende a adoção de medidas socioeconômicas que promovam "uma tomada de consciência da triangularidade da família" e que possibilitem "a todos os seus membros fazer e desfazer conversões entre os diferentes âmbitos de função sem onerosas desvantagens econômicas" (2015, p. 319).

Por último, Honneth avalia que o liberalismo político, o qual, até os dias atuais, está na base da estrutura normativa das sociedades democráticas ocidentais, sempre relegou a família a uma função marginal frente aos processos sociais mais relevantes. Por isso, nunca se refletiu adequadamente como a formação das famílias poderia contribuir para a formação democrática das sociedades. Destaca, assim, a relevância da prática e da socialização de "formas de interação consentidas, democráticas e cooperativas" (2015, p. 321). Dessa forma, conclui Honneth acerca do interesse de toda a sociedade em fomentar a participação da família nas relações socioeconômicas institucionalmente estabelecidas, até mesmo como forma de perpetuação dos hábitos democráticos formados dentro do ambiente propiciado pela entidade familiar como um todo. 


\section{Referências}

CLAASSEN, Rutger. Social Freedom and the Demands of Justice: A Study of Axel Honneth's 'Recht der Freiheit'. Constellations: An International Journal of Critical and Democratic Theory. Berlin, v. 21, n. 1, p. 67-82, 2014.

DE BOER, Karin. Beyond recognition? Critical reflections on Honneth's Reading of Hegel's 'Philosophy of Right'. International Journal of Philosofical Studies. Londres, v. 21, n. 4, p. 534-558, 2013. Disponível em: <http://dx.doi.org/ 10.1080/09672559.2012.760171>. Acesso em: 08 jul. 2019.

HEGEL, Georg Wilhem Friedrich. Linhas fundamentais da filosofia do direito. Tradução: Paulo Meneses et al.. São Leopoldo: Unisinos, 2010.

HONNETH, Axel. O direito da liberdade. Tradução Saulo Krieger. São Paulo: Martins Fontes, 2015.

- Sofrimento de indeterminação: uma reatualização da Filosofia do direito de Hegel. São Paulo: Singular, Esfera Pública, 2007.

. The I in we: studies in the theory of recognition. Cambridge: Polity, 2012.

PEDERSEN, Jorgen. Writing history from a normative point of view: the reconstruction method in Axel Honneth's Das Recht der Freiheit. In: JAKOBSEN, Jonas; LYSAKER, Odin (eds.). Recognition and freedom: Axel Honneth's political thought. Boston: Brill, 2015.

QUONG, Johnathan. On the idea of public reason. In: MANDLE, Jon; REIDY, David (eds.). A companion to Rawls. Chichester: Wiley Blackwell, 2014.

ZURN, Christopher F. Axel Honneth. Cambridge: Polity, 2015.

Recebido / Received: 03/10/2019

Aprovado / Approved: 27/01/2020

Publicado / Published: 20/09/2020 